\title{
Os novos contornos do antissemitismo, a construção de imaginários pela mídia no Brasil e a escrita da História: singularidades e perigos
}

\author{
The new outlines of anti-Semitism, the construction of imaginary by the media in Brazil and the \\ writing of History: singularities and dangers
}

\author{
Ana Heloisa Molina \\ https://orcid.org/0000-0002-3363-5382 \\ Universidade Estadual de Londrina \\ Helena Ragusa \\ https://orcid.org/0000-0002-4719-8523 \\ Universidade Estadual de Maringá
}

\begin{abstract}
Resumo: As recentes ondas de ataques antissemitas e de discursos negacionistas, ainda que com mais força no contexto europeu e norte-americano, reverberaram e vêm ecoando na vida pública brasileira, principalmente no ambiente da Web 2.0. Nosso objetivo é analisar os frequentes episódios de negação da Shoá e de hostilidade e ameaça a grupos que, como os judeus, tornaramse alvos de ódio e racismo nas diversas plataformas digitais e redes sociais existentes. Para tanto, recorremos aos autores que, em seus estudos, atentam-se ao uso do termo antissemitismo e à complexidade sobre ele ao lidar com o conceito nos diferentes tempos e espaços por onde transitam suas análises. Somamos a isso as noções trazidas por Bronislaw Baczko (1985) em torno dos imaginários sociais, de modo a compreender o passado que remete ao fenômeno do antissemitismo e os novos contornos que na atualidade se fazem sentir e que, conforme veremos aqui, não passam despercebidos.
\end{abstract}

Palavras-chave: Antissemitismo. Negacionismo. Internet. Imaginário.

Abstract: The recent waves of anti-Semitic attacks and negative speeches, albeit with greater force in the European and North American context, reverberated and have been echoing in Brazilian public life, especially in the Web 2.0 environment. Our goal is to analyze the frequent episodes of Shoah denial and hostility and threat to groups that, like the Jews, have become targets of hatred and racism on the various digital platforms and existing social networks. To this end, we turn to authors who in their studies pay attention to the use of the term anti-Semitism and the complexity of it when dealing with the concept in the different times and spaces where their analyzes go. We add to this the notions brought by Bronislaw Baczko (1985) around that of social imaginary, in order to understand the past that refers to the phenomenon of anti-Semitism and the new outlines that are currently felt and that, as we will see here, do not go unnoticed.

Keywords: Anti-Semitism. Negationism. Internet. Imaginary.

O imaginário social é, pois, uma peça efetiva e eficaz do dispositivo de controle da vida coletiva e, em especial, do exercício da autoridade e do poder. Ao mesmo tempo, ele torna-se o lugar e o objeto dos conflitos sociais. (BACZKO, 1985, p. 310).

Exemplo 1 (grupo de WhatsApp): em 20/08/2019, um grupo com o nome Fascismo Vive foi criado no WhatsApp com aproximadamente 80 participantes. Nele, um dos integrantes desabafa: "Sou capaz de morrer por este país, queria matar os maçons, os deputados, os sionistas, todos esses hereges." Finalizou com "Heil Hitler", saudação nazista que significa Salve Hitler. Três minutos 
depois, Rael, que tem a figura de uma suástica ao lado de seu nome, respondeu: "Heil Hitler (FOLHA PRESS, 2019, p. 1).

Exemplo 2 (plataforma digital): o canal organizado e produzido por Nando Moura (2015), que conta com 1,5 milhão de seguidores, em sua maioria adolescentes, possui um número significativo de vídeos de caráter ofensivo cujos conteúdos contrariam as narrativas históricas, especialmente aquelas oriundas de profissionais da História, como professores, e também de livros didáticos de História. Uma das afirmações feitas pelo youtuber é que o partido nazista era de esquerda e Hitler teria sido uma "cria" de Karl Marx.

Exemplo 3 (rede social): surge o Pegida (Patriotische Europäer gegen die Islamisierung des Abendlandes) na rede social Facebook, criado em 2014 pelo publicitário alemão Lutz Bachmann, contrário à presença de islâmicos em países europeus, expandindo-se para outros grupos de imigrantes, como os refugiados,(oriundos da guerra da Síria e de países africanos) os quais, no ano de 2015, contabilizaram em torno de 1 milhão nas fronteiras alemãs. O Pegida conta com uma rede ampla de seguidores em diversos cantos da Europa e fora dela e extrapolam o ambiente virtual para manifestações reais organizadas com caráter xenófobo e racista. No Brasil, a página Pegida Brasil (2020), hospedada na rede social Facebook, conta com um número menos expressivo, mas não desprezível: são quase 200 seguidores que compartilham do mesmo sentimento de intolerância em relação aos de origem islâmica e também com outras questões que perpassam pelo multiculturalismo, feminismo, entre outros.

Os exemplos aqui demonstrados ${ }^{1}$ são uma pequena amostra de que, inegavelmente, a mídia se tornou uma ferramenta poderosa na formação da consciência coletiva, impregnando com imagens, gestos, performances e narrativas a construção ou a reconfiguração do que podemos chamar de Outro, aquela figura historicamente colocada como "inimigo", "impuro" ou "detentor de pecados", mormente o destoante da imagem ariana padrão: branca, cristã e europeia.

Em nosso caso, é extremamente interessante verificar como o discurso antissemita, juntamente com outras formas de ódio, aparece na Internet e nos meios digitais, e, dessa forma, analisar como se apresenta o imaginário e com quais imagens (tanto as relacionadas às representações construídas quanto aquelas descritas por adjetivos ou impropérios) são divulgadas nesses meios comunicativos de grande capacidade formadora de opiniões.

Tomamos como imaginário um dos aspectos indicados por Baczko, especialmente aquele concernente aos lugares a serem ocupados em uma determinada hierarquia.

É assim que, através dos seus imaginários sociais, uma coletividade designa a sua identidade; elabora uma certa representação de si; estabelece a distribuição dos papéis e das posições sociais; exprime e impõe crenças comuns; constrói uma espécie de código de "bom comportamento", designadamente através da instalação de modelos formadores tais como o do "chefe", o "bom súdito", o "guerreiro corajoso", etc. Assim é produzida, em especial, uma representação global e totalizante da sociedade como uma "ordem" em que cada elemento encontra o seu "lugar", a sua identidade e a sua razão de ser (BACZKO, 1985, p. 309).

Ao mesmo tempo, notamos uma dimensão maior - em termos de alcance e popularidade dos discursos que assumem o pensamento antissemita presentes nas redes sociais e plataformas digitais, no contexto brasileiro atual, o que define a liberdade de expressão e como os meios digitais lidam com aquilo que denominam de censura de conteúdo.

Essas são algumas das questões que buscaremos responder na tentativa de compreender os novos contornos da ideologia antissemita na virada do século XX para o XXI, a qual muitas vezes

\footnotetext{
${ }^{1}$ No primeiro exemplo, a Folha de São Paulo divulgou que acompanhou "incógnita esse e outros grupos de extremadireita ativos no WhatsApp, a maioria deles formados recentemente" (FOLHA PRESS, 2019, p. 1). No segundo caso, por meio de livre acesso, os vídeos realizados por Nando Moura (2015), como é conhecido na plataforma YouTube, conta com milhares de seguidores, conforme aqui demonstrado. No terceiro exemplo, ao Pegida Brasil (2020) foi enviado há um ano atrás um convite nosso para participar da rede e desde então é possível, por meio das postagens - as quais ocorrem num rito semanal - acessar o conteúdo.
} 
é tratada como uma fase, mas que, ao contrário do que representa tal analogia, a nosso ver, tratase de algo que estaria muito mais próximo a uma ideia de continuidade.

Em um primeiro momento, consideramos que a história de um tempo presente só existe se partirmos de um recuo ao passado, o que significaria ir às origens do antissemitismo e à escrita dessa história no Brasil, para, então, e somente assim, compreender as manifestações diversas que atualmente circulam nos meios digitais em torno das questões que cercam o tema.

Em seguida, propomos uma reflexão acerca dos usos e das apropriações feitas por grupos antissemitas da web $2.0^{2}$ e de outros canais de comunicação para a divulgação e a disseminação de conteúdos supremacistas, racistas e xenófobos, o que inegavelmente elevou o pensamento antissemita para uma perspectiva global, fazendo cada vez mais adeptos, como veremos no caso brasileiro.

Posteriormente, refletiremos acerca das escritas e do imaginário divulgadas e as possíveis leituras que impregnam seus significados. Investigando os portais onde atualmente são disseminados conteúdos nessa vertente, encontramos aqueles que ainda não sofreram impedimento por parte de decisões judiciais e contam com milhares de seguidores.

Para além dos exemplos que introduzem esse texto, elencamos alguns outros, sobre os quais pretendemos nos debruçar um pouco mais, como o site Metapedia ${ }^{3}$ (2011), de origem sueca e fundado em 2006 pelo neonazista Anders Lagerström, e o segundo, de origem norte-americana, o portal $\mathrm{Gab}^{4}$, criado no ano de 2016 pelo fundador e CEO Andrew Torba, em Austin, no Texas, mas que no Brasil tomou o nome de Gab.ai.

Antes de tudo, porém, não podemos ignorar o fato de que, com a Internet, a sociedade vem passando por um grande realinhamento sem precedentes, o que altera os padrões político, comercial e cultural. Sobre isso, Johnny Ryan (2010) explica que:

O padrão definidor da era digital emergente é a ausência do ponto central. Em seu lugar está envolvida uma malha de muitos pontos, cada um deles ligado por webs e redes. Esta história é sobre a morte do centro e o desenvolvimento da vida comercial e política em um sistema em rede. É também a história sobre o poder vindouro do indivíduo em rede como a nova unidade vital de participação efetiva e criatividade. (RYAN, 2010, p. 7). ${ }^{5}$

Os portais aqui em questão têm como público, em geral, adeptos da chamada Alt-Right (direita alternativa) ${ }^{6}$ e a direita política ${ }^{7}$, que, embora diferentes no modo de interação com o público, prometem liberdade, "concentrando-se em tópicos que geralmente não são abordados - ou seja, ficam fora das - enciclopédias convencionais" convidativa" (CARVALHO, 2016, p. 12). No caso da rede social Gab, ela se coloca como um espaço que "defende a liberdade de expressão, liberdades individuais, e o fluxo de informações", um espaço sem censura.

Não caberia aqui uma análise mais aprofundada acerca da dinâmica e dos tipos de discursos

\footnotetext{
2 De acordo com Cristobal Cobo Romaní e Hugo Pardo Kuklinski (2007, p. 15), comparando-a com a World Wide Web, ou apenas Web, criada em 1990, a Web 2.0, seria uma nova fase, "una plataforma abierta, construida sobre una arquitectura basada en la participación de los usuarios".

3 Conforme Bruno Leal Pastor de Carvalho, "[...] a Metapédia, por sua vez, é registrada na cidade norte-americana de Dallas, Texas, mas possui conexões com diversos outros sites, especialmente de extrema-direita" (CARVALHO, 2016, p. 10).

${ }^{4} \mathrm{O}$ site conta com mais de 710 mil usuários cadastrados pelo mundo, dos quais 175 mil estão no Brasil (COSTA, 2018, p. 1).

5 "The defining pattern of the emerging digital age is the absence of the central dot. In its place a mesh of many points is evolving, each linked by webs and networks. This story is about death of the centre and the development of commercial and political life in a networked system. It is also the story about the coming power of the networked individual as the new vital unit of effective participation and creativity". (RYAN, 2010, p. 7).

${ }^{6}$ Um dos matizes da chamada nova direita.

${ }^{7}$ Nesse caso, um dos seguidores, o atual presidente do Brasil Jair Messias Bolsonaro, tornou-se membro da rede social no dia 21/08/2018, sendo saudado pelo fundador da rede, Torba, com um "Wow" e uma imagem onde aparece montado no sapo que identifica esse grupo em específico. (FUCS, 2018).

8 Texto presente na página inicial do site (METAPEDIA, 2011, p. 1).
} 
e conteúdos veiculados por ambos os sites; no entanto, o que há de mais relevante em relação a eles são as tendências negacionista e revisionista da história fortemente vinculados a uma extrema direita, o número de seguidores que chega à marca dos milhares e o fato de que o Brasil não está imune a tal cenário. ${ }^{9}$

De acordo com Jean-François Sirinelli (2003), "[...] cada nova geração de historiador circula num ambiente intelectual, mas também ideológico próprio" (SIRINELLI, 2003, p. 81). O avanço da extrema direita ${ }^{10}$ e do conservadorismo no Brasil atual é certamente reflexo do cenário político europeu ${ }^{11}$. "Adormecidos" no momento em que o integralismo - década de 1930 - perde sua força política, encontram terreno fértil para a propagação de ideias voltadas para uma ameaça comunista no período da Guerra Fria e reacendem com força no período que compreende o golpe de 1964 (CHASIN, 1999).

Mas a isso também somamos o fato de que

Existem, naturalmente, códigos ou um conjunto de referências que estão intrínsecos em partidos políticos e nas demais instituições políticas, mas junto a eles, precisamos sublinhar o peso das ideias, dos mitos, das memórias coletivas e individuais que ajudam a formar uma cultura política ou culturas políticas (PRIORI; BRUNELO, 2018, p. 35).

Da década de 1980 para os dias atuais, a extrema direita no Brasil ganhou novos contornos. A impressão é de que aqui existe um "[...] 'tempo da política', ou seja, períodos em que a população percebe a política e os políticos como parte de sua vida social" (KUSCHNIR; PIQUET-CARNEIRO, 1999, p. 240).

A recém-eleição do capitão reformado Jair Messias Bolsonaro (PSL) à presidência do Brasil como o $38^{\circ}$ presidente desde a redemocratização no ano de 1985 é um exemplo claro de como isso ocorre.

Dentre as "técnicas de persuasão na propaganda eleitoral" do presidente atual duas ao menos merecem destaque: o percurso da construção mercadológica que o levou ao poder e o slogan criado e usado para imprimir a "imagem de marca" que levou ao candidato à simpatia popular, qual seja, "Brasil acima de Tudo, Deus acima de Todos".

A ascensão do ex-deputado federal (1991-2019) à presidência vem chamando a atenção no sentido de privilegiar, dentre outros, a volta dos militares ao centro do poder e a ascensão de uma "nova direita" encabeçada por ministros que não escondem em seus pronunciamentos a defesa do conservadorismo nos costumes da "família brasileira".

Outro dado que chama a atenção é que a campanha eleitoral do recém-presidente eleito foi, ao contrário do que ocorrera em outras eleições, agora muito mais "digital" do que televisiva12: "A cada novo pleito, observamos a comunicação ocupando mais e novos espaços-tempos na função mediadora de levar mensagens de candidatos e partidos ao grande público distante do cenário cotidiano da política" (MACHADO, 2011, p. 1).

O atual presidente da República parece ter compreendido a potência do meio virtual, passando a explorar ao longo de sua campanha os recursos que este oferece, como a escolha de

\footnotetext{
${ }^{9}$ Sobre essa questão, Bruno Leal Pastor de Carvalho (2016) faz uma análise profunda acerca do site Metapedia e a forma como apresenta - nega, ameniza, distorce - o Holocausto.

10 Compreendemos aqui a "extrema direita", a partir da definição dada por João Fábio Bertonha (2012), como "um grupo particular dentro do campo da direita que não se contenta com a manutenção da ordem social como os conservadores e nem restaurar um passado mítico como os reacionários, mas visa, ao menos em teoria, criar algo novo a partir das premissas centrais do universo da direita, destruindo a democracia liberal. Nesse sentido, considero os fascistas como membros da direita radical, mas que essa não se limita a eles" (BERTONHA, 2012, p. 135).

${ }^{11}$ Cenário esse que vem numa curva ascendente desde o fim do século XX, fortalecendo-se em democracias de todo o mundo, vinculado aos efeitos da globalização (BETZ, 1993).

${ }_{12}$ Algo que vem se configurando no cenário político brasileiro desde 2010 e que, podemos afirmar, veio a consolidar-se fortemente ao menos nesta última eleição.
} 
uma rede social, na qual chegou a quase 20 milhões de seguidores ${ }^{13}$.Esquivando-se dos debates televisivos - especialmente no $2^{\circ}$ turno -, Bolsonaro encontrou na Internet um espaço onde pôde construir seu "marketing social". Ao utilizar-se de ferramentas que facilitavam a divulgação de seu plano de governo, o atual presidente teve uma aproximação maior com o grande público, interagindo com ele em tempo real ${ }^{14}$.

A Internet surge então como um espaço onde a força do engajamento ideológico orquestrado pela extrema-direita - um dos grupos de pressão que a circunda - encontra um campo ainda mais fértil, especialmente com a ascensão dessa "nova direita" que emerge no Brasil. Dono de pronunciamentos polêmicos, muitos deles quando ainda ocupava o cargo de deputado federal, Bolsonaro surge como "defensor da Ditadura Militar e de torturadores, desgostoso pelas "poucas" mortes ocorridas nos anos de chumbo, senhor de frases homofóbicas, racistas e machistas" (FIORUCCI, 2017, p. 11). Seguido por milhares de pessoas e agora ocupando um cargo de liderança, o cenário que se apresenta é, no mínimo, preocupante, porque propício para o comportamento daqueles que insistem na negação de eventos históricos amplamente comprovados.

Podemos perceber esse avanço pelas pesquisas da antropóloga Adriana Dias, que, desde 2002, vem investigando o nazismo na Internet. No começo, suas análises se davam em sites individuais com tendências neonazistas no país, mas, agora, o estudo abrange os fóruns coletivos onde observa num deles, por exemplo, uma postagem antissemita a cada quatro segundos; uma postagem racista contra negros, pessoas com deficiência e LGBTs a cada 8 segundos (DIAS, 2018). A autora revela o quanto o cenário é preocupante quando identifica:

\begin{abstract}
Movimentos brasileiros bem organizados, como o Neuland ("nova" terra), liderado por Ricardo Barollo. "Conhecia o grupo, mas não sabia que Barollo era o líder, apenas que se tratava de uma pessoa de São Paulo, com perfil universitário, e que sua célula possuía em torno de 200 membros, por conta da circulação de material. Em 2009, em disputa pelo poder, ele matou o diretor de outra célula, Bernardo Dayrell (e também a namorada), criador da revista online $O$ Martelo. Tentou culpar os judeus pelo duplo homicídio, mas acabou preso e o grupo, desbaratado. O Neuland queria eleger vereadores e prefeitos em duas cidades de Santa Catarina e do Paraná, e assim ir ganhando força para tomar os estados do Sul e São Paulo, em um movimento separatista" (DIAS, 2018, p. 1).
\end{abstract}

Deste modo, "fabricada" ou "condicionada", fato é que a opinião pública merece atenção. Jean Jacques Becker (2003), no texto intitulado "A opinião pública", alerta sobre a escassez de estudo sobre esse fenômeno. Segundo ele, o comportamento das massas diante dos acontecimentos parece ter escapado à produção histórica.

Um país como o nosso, em que o racismo ainda se apresenta como um desafio, o indígena é compreendido como "indolente" e "preguiçoso"15, os delitos graves cometidos pela ditadura são colocados em dúvida e o comunismo perpetua-se como uma ameaça constante, torna-se terreno fértil para que fenômenos como o negacionismo sejam acolhidos, compartilhados e vivenciados. Por esta razão,

Estudar uma cultura política, ou melhor, trabalhar com sua formação e divulgação - quando, quem, através de que instrumentos -, é entender como uma certa interpretação do passado (e do futuro) é produzida consolidada, integrando-se ao imaginário ou à memória de grupos sociais, inclusive os nacionais (GOMES, 2005, p. 31).

\footnotetext{
${ }^{13}$ No caso, a rede é o Facebook, que atingiu cerca de 127 milhões de usuários ativos mensais, representando $65 \%$ da população com 10 anos ou mais. (OLIVEIRA, 2018).

14 Referimo-nos aqui às chamadas lives, uma função que permite aos internautas realizar transmissões ao vivo diretamente de um dispositivo Android ou IOS.

15 Declaração presente no discurso proferido pelo então candidato a vice presidente General Antônio Hamilton Mourão (PRTB), mais conhecido como General "Mourão", ao participar, em Caxias do Sul, do primeiro evento público após ser anunciado na chapa presidencial no dia 06/08/2018 (PODER360, 2018).
} 
$\mathrm{Na}$ conjuntura política atual, repete-se o fato de que "não é o fantasma do comunismo, mas os agentes de carne e osso de grupos e partidos que dialogam com o fascismo e extremismos diversos" (FIORUCCI, 2017, p. 12).

Ainda que venha a tratar-se de uma história voltada para o "tempo breve", "delimitado", se considerarmos o recente desenlace eleitoral no cenário político brasileiro e tomarmos a imprensa jornalística e a Internet - esses "espíritos independentes" reflexo de "grupos de pressão diversos" (BECKER, 2003, p. 189) -, como fontes teremos uma rica possibilidade, tanto no sentido qualitativo como quantitativo, de analisar o peso das opiniões que nela são emitidas.

O primeiro passo para iniciarmos nossa discussão seria compreender o que de fato caracteriza o antissemitismo na contemporaneidade, como circula e por onde se expressa. Uma questão complexa certamente, razão pela qual optamos pelos três casos expostos logo no início deste texto, perguntando-nos se esses devem ou não ser definidos como antissemitas.

Em nossa concepção, por meio de exemplos concretos, é possível melhor entender não só o que vem a ser o antissemitismo, mas também suas expressões, identificando-as nos diversos espaços em que ocorrem.

\section{0 antissemitismo quando ainda era antijudaísmo}

"A condição das comunidades judaicas é marcada por traços da heterogeneidade no espaço e da descontinuidade no tempo", assim compreende Gérard Rabinovitch (2004, p. 31), quando se refere à história do povo judeu e à instabilidade permanente responsável pelos massacres cíclicos, agravados por uma gama de sentimentos dos quais o ódio é o mais antigo e se encontra na base do antissemitismo, conforme constata Ruth Wodak (2009) em seu estudo acerca do ódio, do racismo e do preconceito.

Tratar da História do Antissemitismo é adentrar no universo judaico, o que não é uma tarefa fácil, pois envolve uma miscelânea de ideias atrelada a sentidos e significados de caráter religioso e, de acordo com Lesser e Cytrynowicz, no prefácio do livro de Michael Brenner (2013),

O distanciamento essencial para o ofício do historiador é prejudicado quando ouvimos dizer que os judeus são o "Povo Eleito de Deus" ou são "deicidas", quando a "inteligência judaica" é louvada ou as "finanças judaicas internacionais" são estigmatizadas, quando Israel é elogiado como um contraforte da civilização em meio a barbárie ou condenado como um regime brutal em meio a países que amam a paz (LESSER; CYTRYNOWICZ, 2013, p. XXX).

Outra dificuldade se deve ao fato de tratar-se de uma história tardia, quase sempre vinculada ao Holocausto, o que dificulta outras possibilidades de percepção acerca do povo judeu que não se limitem apenas ao genocídio e às perseguições perpetradas contra esse povo, evitando a ideia de um "antissemitismo preexistente" (LESSER, 2013, p. XXX).

Até mesmo no que se refere ao território alemão, ao identificar a presença judaica já desde o século I d.C. como algo indesejável, Pierre Sorlin (1974) atribui tal fato à Igreja, a qual, mesmo concedendo liberdade religiosa aos de origem hebreia, não suportava o fato deles receberem privilégios ${ }^{16}$ de alguns soberanos, como viverem de acordo com seus costumes ou ocuparem altos cargos, por exemplo.

Em seu estudo, Bila Sorj (2007) nos alerta para os perigos existentes em usar antissemitismo, termo abrangente, para designar um fenômeno mais antigo, fazendo surgir explicações "a-históricas" que levariam, segundo ela, ao "empobrecimento" da interpretação sobre ele, tornando difícil a compreensão acerca dos "diferentes significados e formas de expressão em contextos societários específicos” (SORJ, 2007, p. 97).

\footnotetext{
${ }^{16}$ Acerca dessa questão, Pierre Sorlin esclarece que os judeus não eram os únicos a receber o que chama de direitos especiais, mas outros grupos estrangeiros radicados em território alemão também eram beneficiados (SORLIN, 1974, p. 16).
} 
Por esta razão, consideramos o termo antijudaísmo o mais adequado para todo e qualquer discurso de ódio designado aos judeus, ao menos até a ascensão das teorias racistas no contexto europeu da segunda metade do século XIX e que se estenderam por todo século XX, chegando até a atualidade.

Ao analisarmos as permanências existentes no fenômeno do antissemitismo, identificamos o fator religioso como o principal elemento que muito contribuiu para fortalecer as ações, atitudes e pensamentos que buscavam justificar o ódio contra os judeus. De acordo com Morin (2007, p. 17), "nos três primeiros séculos cristãos, o antijudaísmo foi, em primeiro lugar, teológico até que passasse para o que ele denomina de antijudaísmo popular", quando os judeus passaram então a ser acusados de todo tipo de tragédia e catástrofes sofridas ao longo do período. Arraigado na tradição ocidental, o termo antijudaísmo se aplicava a todos os judeus que não se encaixavam nos "moldes agostinianos"17, portanto eram hereges, deicidas (COHEN, 1982).

David Nirenberg (2014) considera o antijudaísmo como um modo de observância do cristão para consigo mesmo e para com os outros no intuito de não incorrer em qualquer ato judaizante, para não judaizar, como uma ideologia, portanto, poderosa, muito mais do que aquilo que se passou a considerar como antissemitismo na modernidade.

A demonização do judeu difundida por todo medievo continuou sendo usada até mesmo quando as ideias políticas encontraram no pensamento antissemita uma ferramenta importante para excluir e eliminar esse grupo, como vimos acontecer na Alemanha Nazista de Hitler ${ }^{18 .}$

Desse modo, compreendemos que, sem o estatuto teológico, o antissemitismo, por si só não se explica, não é suficiente e, "[...] se as nações modernas emanciparam os judeus reconhecendoos como cidadãos, permaneceu no povo e nas elites a herança de um antijudaísmo cristão" (MORIN, 2007, p. 69).

Gérard Rabinovitch (2004) explica essa questão muito claramente quando percebe o substrato cristão fortemente presente na democracia que ascende no decorrer do século XIX na Europa; segundo o autor, o fato de as autoridades eclesiásticas terem perdido a influência política não abalou o "coração dos combatentes os mais seculares a pregnância antijudaica do paganocristianismo" (RABINOVITCH, 2004, p. 33).

Refletindo acerca de outros espaços onde o legado antijudaico se instaurou, para além do território europeu, tão logo começaram as colonizações de novas terras empreendidas pelos reis e majestades do mundo Ibérico, a presença judaica já trazia um clima de mistério e dúvida. Sendo em grande parte judia, conversos expulsos da Espanha e de Portugal ou em fuga da intolerância sofrida nestes reinos, passaram a integrar as sociedades que nesses espaços foram se formando. A estranheza sobre esses agentes suscitada em grande parte pela lgreja e seus representantes gerou entre os habitantes uma desconfiança em torno daquele que não era judeu e também não era cristão.

Diferentemente do que veremos ocorrer nos países europeus, o antijudaísmo, esse sentimento "importado" que chegará a lugares como o Brasil, por exemplo, será muito mais determinante na construção de estereótipos e distorções em torno da presença judaica do que o antissemitismo em si, como foi o caso da Alemanha nazista.

O que há em comum num espaço de tempo tão distante entre as realidades que ora apresentamos é que a condição de outsider sempre foi uma nódoa para os judeus de qualquer parte do mundo. Conforme explica Hanna Arendt, onde estivessem, ainda que fizessem o melhor para provarem para as pessoas que eram somente ordinários imigrantes, ainda assim os judeus eram, aos olhos dos outros, um estrangeiro (ARENDT, 1994, p. 110).

Devemos estar atentos aos perigos de projetar "sobre a história do passado nossas

\footnotetext{
17 Sobre esse assunto, ver Jeremy Cohen (1982), em seu estudo acerca da evolução do antijudaísmo na Idade Média.

${ }^{18}$ A luta contra o jüdischer Geist ou "espírito judaico", do qual nos fala Dan Michman (2011), em seu estudo acerca da perseguição sofrida pelos judeus na Alemanha nazista.
} 
preocupações atuais" (SORLIN, 1974, p. 16). De acordo com Ruth Wodak (2018), o antissemitismo mudou ao longo dos séculos:

Somos confrontados com duas novas formas de anti-semitismo que surgiram após a Segunda Guerra Mundial: anti-semitismo secundário e anti-semitismo relacionado a Israel e "Sionismo". Muito semelhante ao antijudaísmo (ou seja, anti-semitismo de base religiosa) e a ambos, antisemitismo moderno e tradicional, ambas as novas variantes referem-se ao imaginário de um coletivo judeu homogêneo. Este coletivo, de acordo as proeminentes teorias de conspiração mundial, é percebido como uma luta pelo poder em todos os domínios socialmente relevantes; alternativamente, tais teorias afirmam que o "coletivo judeu" já alcançou tal poder e está abusando dele - afirmações que frequentemente são combinadas com sentimentos antiamericanos (WODAK, 2018, p. 4) ${ }^{19}$.

Enzo Traverso (2016) acrescentará ao debate o novo rosto do antissemitismo, uma nova categoria desvinculada agora de uma orientação hierárquica e racialista, mas que se confunde quando há uma:

[...] tendência a incluir fenômenos de diferentes naturezas: antijudaísmo religioso, ateísmo iluminista, anti-semitismo racista, anti-sionismo de esquerda ou direita, e, finalmente, as críticas à política israelense, são sistematicamente reduzidas a uma matriz única, da qual são supostamente apenas expressões externas de uma longa e ininterrupta história ${ }^{20}$ (TRAVERSO, 2016, p. 83).

Fato é que antijudaísmo, antissemitismo ou antissionismo ${ }^{21}$, nenhum desses termos parece ser suficiente quando se busca explicar o ódio em relação aos judeus; é preciso, então, atentar para as novas judeofobias entre antissemitismo e antissionismo (TRAVERSO, 2016, p. 83).

As considerações trazidas por Enzo Traverso estão presentes na escrita do filósofo, cientista político e historiador das ideias Pierre-André Taguieff (2016), o qual realiza uma revisão acerca das novas configurações antijudaicas compreendendo o antissemitismo como um "conjunto de reações contra a emancipação dos judeus. Portanto, parece ser um produto da era moderna"22 (TAGUIEFF, 2016, p. 1). O autor explica ainda que,

Nesta nova forma de judeofobia, já não se trata de distinguir entre diferentes categorias de judeus: cada judeu, por ser judeu, é designado como encarnando o "perigo judeu". Esta é a primeira consequência prática, com consequências políticas de longo alcance, da disseminação da ideologia anti-semita (TAGUIEFF, 2016, p. 1).

Os discursos religiosos contrários ao judeu e a propaganda nazista perpetuam-se, é verdade, porém agora ressignificados em outros espaços, além de se estenderem para outros grupos conforme vimos há pouco nas constatações trazidas por Adriana Dias constituindo um vasto campo de atuação e disseminação também no Brasil.

\section{O lugar das redes sociais na disseminação do antissemitismo no Brasil}

\footnotetext{
19 "Moreover, we are confronted with two new forms of antisemitism that emerged after the Second World War: secondary antisemitism and antisemitism related to Israel and "Zionism." Quite similar to anti-Judaism (i.e., religiously based antisemitism) and to both modern and traditional antisemitism, both new variants refer to the imaginary of a homogeneous Jewish collective. This collective, according to prominent world conspiracy theories, is perceived to strive for power in all socially relevant domains; alternatively, such theories claim that the "Jewish collective" has already achieved such power and is abusing it—claims that are frequently combined with anti-American sentiments." (WODAK, 2018, p. 4).

20 "[...] tendency to include phenomena of different natures: religious anti-Judaism, Enlightenment atheism, racist antiSemitism, left- or right-wing anti-Zionism, and finally criticism of Israeli policy, are systematically reduced to a single matrix, of which they are supposedly only outward expressions of a long and uninterrupted history" (TRAVERSO, 2016, p. 84).

${ }^{21} \mathrm{Na}$ prática, significa negar o direito dos judeus em se considerarem uma nação, portanto seriam contrários à criação do Estado de Israel.

22 "L'ensemble des réactions contre l'émancipation des Juifs. II apparaît donc comme un produit de l'époque moderne" (TRAVERSO, 2016, p. 83).
} 
"Ao lado da perpetuação do antijudaísmo clássico desenvolve-se um antissemitismo político, social ou nacionalista, progressista ou reacionário" (RABINOVITCH, 2004, p. 33). É ao final da década de 1870 que a palavra antissemitismo surgirá pela primeira vez na Alemanha, até se tornar um programa político.

No contexto de uma crise democrática, o ódio aos judeus não será - assim como não é hoje - algo exclusivo da direita, mas também da esquerda. O judeu surgirá nesse cenário como um explorador das classes menos favorecidas, ao mesmo tempo como um cosmopolita que pretende dominar o mundo. Ambas as formas de conceber o judeu, embora diferentes, o têm como inimigo e concordam com sua eliminação.

O antissemitismo do qual falaremos aqui, portanto, é aquele imbuído do antijudaísmo clássico, mas que encontrará nas bases das teorias raciais uma espécie de validação pseudocientífica para os discursos antidemocráticos que emergirão no decorrer do século XIX. Somamos a isso a ideia de uma "Judeofobia pós-anti-semita contemporânea, estruturada pelo antissionismo radical” (L'ARCHE MAGAZINE, 2016, p. 1).

Mesmo após uma década passada da $2^{\mathrm{a}}$ Guerra Mundial, as campanhas antijudaicas continuaram. A constatação é de que, nas palavras de Pierre Sorlin (1974) e suas impressões acerca do antissemitismo alemão, "cancelou-se o passado, os judeus desapareceram, o antissemitismo continua vivo" (SORLIN, 1974, p. 94).

Uma situação inusitada aconteceu recentemente. Divulgado pela Embaixada da Alemanha no Brasil, em setembro de 2018, em suas redes sociais, o vídeo que mostra o modo como a Alemanha lida com a história do nazismo gerou polêmica. Um grupo de brasileiros resolveu contestar a Embaixada da Alemanha sobre o nazismo ${ }^{23}$ chegando a negá-lo, algo que na Alemanha é considerado crime.

Como já dissemos, contar a história dos judeus não é uma tarefa fácil, principalmente quando "[...] praticamente todos os povos da Terra não só já ouviram falar do povo judeu como têm uma opinião formada sobre ele" (LESSER, 2013, p. XXX). Em estudos anteriores, ${ }^{24}$ foi-nos possível constatar que, apesar de uma significativa produção historiográfica em torno dos judeus e também de sua presença em solo brasileiro, há ainda muito que se fazer, principalmente quando levamos essa discussão para fora dos muros acadêmicos.

Os estudos em torno dos judeus e do antissemitismo no Brasil são recentes ${ }^{25}$ e aos poucos ultrapassam as fronteiras da academia. A ruptura desse silêncio contribuiu para a compreensão de que essa identidade não esteve apartada da nossa, ao mesmo tempo em que se trata de um passado que se cruza com o nosso. A opinião dos brasileiros a respeito do vídeo exibido pela Embaixada da Alemanha em sua rede social revela não só um desconhecimento da História da $2^{a}$

\footnotetext{
${ }^{23} \mathrm{O}$ vídeo em questão foi publicado na rede social da Embaixada da Alemanha, no Facebook, e gerou forte polêmica entre os internautas. Dezenas de usuários brasileiros contestaram os fatos históricos referentes ao período, questionando, por exemplo, o número de judeus mortos nos campos de concentração e a própria Shoah (RAGUSA, 2018, p. 341-343).

${ }^{24}$ Referimo-nos aqui especialmente à geração de historiadores liderada pela professora Anita Novinsky, a qual, no final da década de 1980, passa a publicar os estudos que, direta ou indiretamente, traziam a figura do judeu formada por Ronaldo Vainfas, Laura de Melo e Souza, Luis Mott, Maria Luiza Tucci Carneiro, Lina Gorenstein, Lana Lage, Luis Nazario e outros (NOVINSKY, 2009, p. 2-3).

${ }^{25}$ Maria Luiza Tucci Carneiro (2012) faz esse balanço ao tratar da historiografia do antissemitismo no Brasil, começando por ela própria e sua pesquisa de doutorado intitulada $O$ anti-semitismo na era Vargas: fantasmas de uma geração (1930 - 1945), realizada no ano de 1987, vindo a ser publicada no ano de 2001 numa edição ampliada pela Editora Perspectiva. Alguns anos depois, numa espécie de continuidade desse primeiro estudo, a autora realizou outras publicações, dentre elas a de maior destaque: Cidadão do Mundo: o Brasil diante do Holocausto e dos judeus refugiados do Nazifascismo (1933-1948), onde expande o campo de observação para o período que corresponde ao governo do General Eurico Gaspar Dutra (1946-1950) (CARNEIRO, 2010). Avraham Milgram (1994), museólogo e historiador, traz, no início da década de 1990, um trabalho inédito onde busca investigar a política imigratória brasileira e sua atuação quanto à emissão dos vistos aos judeus convertidos ao catolicismo, uma questão que permanece latente ainda nas suas produções mais recentes como aquelas que dão voz aos Justos das Nações, não judeus que arriscaram suas vidas para salvar judeus sem exigir nada em troca (MILGRAM, 2017). Entram para o rol de historiadores dedicados ao tema do antissemitismo no Brasil o brasilianista Jeffrey Lesser (1995; 2005) e Roney Cytrynowicz (2002), os quais, muito embora apresentem perspectivas que contrariam algumas questões suscitadas por Carneiro, trazem à luz do debate o fenômeno antissemita.
} 
Guerra e do Holocausto, mas também sobre quem vem a ser o judeu.

Que a negação do Holocausto ou Shoah impacta na produção e circulação do conhecimento histórico, inclusive no conhecimento histórico escolar, não temos dúvida. Mas, quando os discursos ou as ideias que se intitulam revisionistas passam a ocupar espaços de maior audiência e recepção, então a ameaça à produção do conhecimento histórico se torna maior. É preciso admitir: as "plataformas digitais subverteram as bases da produção e circulação das narrativas sobre o passado" (MALERBA, 2017, p. 142), trouxeram um novo perfil de leitor/consumidor de história, o qual:

Não é mais o especialista, nem sequer o indivíduo educado, como no século XIX e praticamente todo o século XX. Blogs e redes sociais, por exemplo, não aceitam o "textão". A informação e a análise devem se veicular em gotas. A capacidade e a disponibilidade de leitura hoje contam-se em dígitos (MALERBA, 2017, p. 142).

O que temos então é uma ampliação do público leitor da história, dos usos públicos do passado e de formas de compreensão desse passado, situações essas que desafiam o trabalho do historiador no sentido de como essas narrativas vêm sendo organizadas, por quem, atendendo quais demandas e com quais objetivos, ou seja, ocorre a complexificação da produção de conhecimentos, oferecendo novas versões e negociando resultados e sentidos.

No caso do negacionismo e do antissemitismo, o que percebemos é a ocorrência do aumento de grupos e indivíduos que aderem e vêm aderindo aos espaços onde os discursos se constroem e são divulgados, como as redes sociais, por exemplo.

A difusão dessas ideias no Brasil não é uma novidade. Desde a década de 1980 já havia espaços onde o pensamento antissemita e negacionista circulava ${ }^{26}$; em meados da década de 1990, a situação, com a evolução da Internet, se agrava. Fóruns on-line e blogs tornam-se novas vias de acesso aos conteúdos. É preciso levar em conta, contudo, que, ao contrário do que hoje ocorre, os criadores desses blogs e fóruns pareciam se preocupar mais com o público que poderia acessá-los, colocando algumas regras e restrições até serem convencidos de que não seriam denunciados ou que não estivessem sendo espionados. Nos dias atuais, esse controle ou esse receio parece não mais existir. Aplicativos de celulares e mídias sociais, para além das plataformas digitais, parecem verdadeiros "portais", os quais, fincados sobre o discurso da liberdade de expressão, ${ }^{27}$ vêm conquistando um número cada vez maior de seguidores.

A construção dessas narrativas baseadas em um falacioso discurso de liberdade de expressão carrega algumas implicações perniciosas, como o negacionismo e a refutação de pesquisas históricas fundadas em documentos textuais de toda natureza e audiovisuais, engendrando a manutenção de estereótipos e reforçando linhas preconceituosas existentes no imaginário social.

\section{Os significados discursivos, o imaginário e a escrita da História}

Consideramos necessário retomar alguns conceitos como representações e imaginário para

\footnotetext{
${ }^{26}$ Sobre essa questão, ver Odilon Caldeira Neto e o caso da Revisão Editora, fundada no final da década de 1980 por Siegfried Ellwanger, no Rio Grande do Sul, e que promovia "a distribuição de livros com forte teor anti-semita e racista, muito deles de autores negacionistas" (CALDEIRA NETO, 2009, p. 1110).

27 Para não estender em demasia as apropriações sobre esse tema, tomamos como liberdade de expressão aquela constante na Constituição brasileira de 1988, que traz a garantia da liberdade de pensamento, expressão e/ou manifestação expressamente nos itens: o inciso IV, do artigo $5^{\circ}$, afirma que "é livre a manifestação do pensamento, sendo vedado o anonimato", e, continua, no inciso IX, que garante ser "livre a expressão da atividade intelectual, artística, científica e de comunicação, independentemente de censura ou licença". Mas, considera também as consequências e resultados das falas: no "inciso $\mathrm{V}$, é assegurado o direito de resposta, proporcional ao agravo, além da indenização por dano material, moral ou à imagem"; sem esquecer o que prescreve o "inciso X: são invioláveis a intimidade, a vida privada, a honra e a imagem das pessoas, assegurado o direito a indenização pelo dano material ou moral decorrente de sua violação; [...]".
} 
refletir acerca da escrita da História e a construção de significados discursivos nos casos apresentados anteriormente.

Para Chartier (2002), as representações que as sociedades constroem ao longo da História sobre si e para o outro, bem como as classificações e hierarquias em seu interior, são mutáveis no tempo e no espaço, contribuindo para a configuração do mundo social.

As representações e as classificações são organizadas por um conjunto de práticas discursivas, sociais e políticas, em constante conflito e "estão inseridas em um espaço de luta, em que um grupo busca impor a outros sua concepção de mundo, legitimando-se através de sua capacidade de "fazer crer" (MAGALHÃES, 2016, p. 95).

O "fazer crer" encontra-se imbricado em elementos constituintes do imaginário coletivo.

Esse, segundo Baczko (1985), pode ser compreendido como um conjunto de representações coletivas associadas ao poder. Nesse sentido, o autor destaca a natureza política do imaginário social, marcado por um conflito que busca a apropriação e utilização das representações coletivas por meio da construção ou (re)adequação de imagens visuais, verbais e mentais produzidas pelas sociedades.

Podemos ter no horizonte também as considerações de Castoriadis, para quem o imaginário designa

[...] alguma coisa "inventada" - quer se trate de uma invenção absoluta ("uma história inventada em todas as suas partes") ou de um deslizamento, de um deslocamento de sentido, onde símbolos já disponíveis são investidos de outras significações normais ou canônicas (CASTORIADIS, 1982, p. 154).

Nesse aspecto, o uso de determinadas palavras e imagens associadas aos judeus e divulgadas em meios digitais propõe a manutenção de determinadas ideias, reforçando estereótipos. Vejamos alguns elementos dos casos 1 e 3 apresentados no início deste texto.

Grupos extremistas em WhatsApp têm aumentado o número de adesões de participantes e se espraiado em ação, especialmente a partir de 2015, com a onda do fortalecimento de nacionalismos e neonacionalismos em todos os recantos do globo.

Criado em 20 de maio de 2019, o grupo Recrutamento Fascista, com a mesma diretriz do grupo Fascismo Vive, tinha até aquele momento 87 integrantes e possuía entre seus motes: "antissionismo, contra tudo e todos que propagam e financiam o Estado de Israel" e "antiglobalismo contra toda agenda da ONU e toda degeneração imposta pela putada internacional" (ZANINI, 2019, p. 1).

Se considerarmos a importância do domínio do imaginário e do simbólico como lugar estratégico para que o poder possa ser melhor exercido, não podemos nos furtar a perceber como palavras de ordem como "contra tudo e todos" e "degeneração imposta pela putada internacional" legitimam as imagens que esses grupos têm de si próprios, como também dos inimigos a serem combatidos, defendendo um nacional ou um nacionalismo pautado em uma ideia de limpeza de etnias impuras ou daqueles que desafiam ou destoam do que seja considerado "normal" ou "regra" social, ou seja, amplificam "as técnicas de argumentação e persuasão (Retórica), realçando a influência exercida pelo discurso sobre as 'almas' e, nomeadamente, sobre a imaginação e os juízos de valor [cf. Finley 1965]" (BACZKO, 1985, p. 300-301). ${ }^{28}$

Lembremos que o termo degeneração nos remete também a questão de moralidade. Seus sinônimos como indecência, imoralidade, impudicícia, indecoro, cupidez, depravação e

\footnotetext{
${ }^{28}$ Sobre a discussão acerca do manuseio das palavras e a construção de uma determinada linguagem ver Klemperer (2009), cuja tese é que a consolidação do nazismo ocorreu quando este dominou a linguagem: "O nazismo se embrenhou na carne e no sangue das massas por meio de palavras, expressões ou frases, impostas pela repetição, milhares de vezes, e aceitas mecanicamente. [...] Palavras podem ser como minúsculas doses de arsênico: são engolidas de maneira despercebida e aparentam ser inofensivas; passado um tempo, o efeito do veneno se faz notar." (KLEMPERER, 2009, p. 14).
} 
desonestidade abarcam um espectro de qualidades negativas e possuem linhas que vão da sexualidade (cupidez, depravação, impudicícia) ao comportamento recriminatório (desonestidade). Atentamos também que o termo remete à repressão da expressão de arte moderna realizada pelo regime nazista, no que se chamou "arte degenerada" ${ }^{29}$, mas suas raízes encontram-se em ideias formuladas anteriormente e que foram naturalizadas pelos teóricos do Terceiro Reich.

A classificação de algumas manifestações artísticas como degeneradas, em oposição a obras "sadias" (em alemão gesund), é anterior à fundação do próprio Partido Nacional-Socialista e remonta a movimentos culturais racistas na Alemanha do fim do século XIX. Como termo técnico oriundo da biologia, entartet é utilizado para descrever determinados animais ou plantas que foram tão modificados a ponto de não ser reconhecidos mais como parte de uma espécie. $A$ transposição para a esfera da cultura se dá em estudos pseudocientíficos, como o Entartung [Degeneração ou Corrupção], de Max Nordaus, publicado em 1892, no qual o autor defende a superioridade da cultura tradicional alemã ao mesmo tempo em que difama as obras dos simbolistas e dos pré-rafaelitas, procurando provar o quanto são degeneradas ou decadentes, segundo os parâmetros de uma arte considerada espiritualmente "saudável". Com o florescimento da arte moderna na Alemanha no decorrer da década de 1920, teses como a de Nordaus têm a popularidade renovada. São desenvolvidos estudos para provar as relações entre raça e estilo artístico, que servem para consolidar a posição da pintura de gênero realista alemã do século XIX como a expressão mais nobre da raça ariana.

Em 1928, utilizando-se das idéias de Nordaus, o arquiteto e teórico racista Paul SchultzeNaumburg publica o livro Kunst und Rasse [Arte e Raça], no qual aparece pela primeira vez a associação da arte moderna com o termo entartet. $O$ autor coloca lado a lado fotografias de pessoas deformadas ou doentes mentais e pinturas de importantes artistas modernos como Amedeo Modigliani (1884 - 1920), Karl Schmidt-Rottluff (1884 - 1976) e Otto Dix (1891 - 1969) a fim de provar visualmente o caráter "degenerado" da produção moderna. Assim, quando Hitler passa a governar o país, em 1933, o uso dos adjetivos "degenerado" e "sadio" já está suficientemente estabelecido no meio cultural como norma de diferenciação entre a arte de vanguarda e a arte tradicional (ENCICLOPÉDIA, s.v. Arte degenerada).

O termo putada, colocado como impropério, remete ao outro, àquele oriundo de relações extraconjugais, que não é puro ou digno de pertencer a uma sociedade familiar refinada e civilizada nos parâmetros colocados dentro do circuito ideal criado nos imaginários desses grupos nacionalistas. Dessa forma, a desqualificação, mesmo esvaziada e naturalizada em vários momentos do discurso, reforça o Nós, seres puros, e os Outros, os não legítimos, a ocupar determinado lugar, delineando imagens dos inimigos e dos amigos, de rivais e de aliados.

As situações conflituais entre poderes concorrentes estimulavam a invenção de novas técnicas de combate no domínio do imaginário. Por um lado, estas visavam a constituição de uma imagem desvalorizada do adversário, procurando em especial invalidar a sua legitimidade; por outro lado, exaltavam através de representações engrandecedoras o poder cuja causa defendiam e para o qual pretendiam obter o maior número de adesões (BACZKO, 1985, p. 300).

Outra fala produzida pelos integrantes da Corrente Nacionalista, grupo de WhatsApp criado em 06 de agosto de 2019, que conta com 201 participantes e se define como um "grupo nacionalista da Terceira Política" (termo utilizado pela extrema direita para se distinguir dos liberais capitalistas e dos comunistas) é pertinente para nossa análise: "tem que criar um Exército particular e exterminar comunistas e LGBTs" e é significativa, pois o verbo exterminar e o argumento marcial

\footnotetext{
${ }^{29}$ Em 19 de julho de 1937 é aberta na cidade de Munique, na Alemanha, a exposição que marca o apogeu da campanha pública do regime nazista contra a arte moderna: a mostra internacional "Arte Degenerada". Organizada pelo presidente da Câmara de Artes Plásticas do Reich, Adolf Ziegler, a exposição reuniu cerca de 650 obras entre pinturas, esculturas, desenhos, gravuras e livros, provenientes de acervos de 32 museus alemães, consideradas artisticamente indesejáveis e moralmente prejudiciais ao povo, pelo governo nacional-socialista alemão (1933-1945), liderado por Adolf Hitler. Os nazistas classificam como "degenerada" (entartete) toda manifestação artística que insulta o espírito alemão, mutila ou destrói as formas naturais ou apresenta de modo evidente "falhas" de habilidade artístico-artesanal. Em termos visuais, é degenerada toda obra de arte que foge aos padrões clássicos de beleza e representação naturalista, em que são valorizados a perfeição, a harmonia e o equilíbrio das figuras. Nesse sentido, a arte moderna, com sua liberdade formal de cunho fundamentalmente antinaturalista, é considerada em sua essência "degenerada".
}

SÆECULUM - Revista de História [v. 25, n. 43]. João Pessoa, p. 361-379, jul./dez. 2020, ISSNe 2317-6725 
na criação de um exército particular ou milícias financiadas incitam a violência e a validade de seus atos, especialmente aqueles voltados para os que estão fora da curva do pensamento e do comportamento considerado por esses grupos como normal ou ideal. Isso nos remete novamente à indagação de Baczko: "Não são as ações efetivamente guiadas por estas representações; não modelam elas os comportamentos; não mobilizam elas as energias; não legitimam elas as violências?" (BACZKO, 1985, p. 298).

O discurso textual opera determinadas funções de convencimento e legitimidade. O discurso visual, porém, reforça inúmeras ideias e promove sensações que vão do aplauso ao deboche e à repulsa. A imagem abaixo se encontra na reportagem da Folha de São Paulo do dia 24 de agosto de 2019, quando da matéria sobre o crescimento de grupos no WhatsApp que negam o holocausto e propagam o nazismo.

Figura 1: Imagem extraída de grupos de WhatsApp neonazistas.
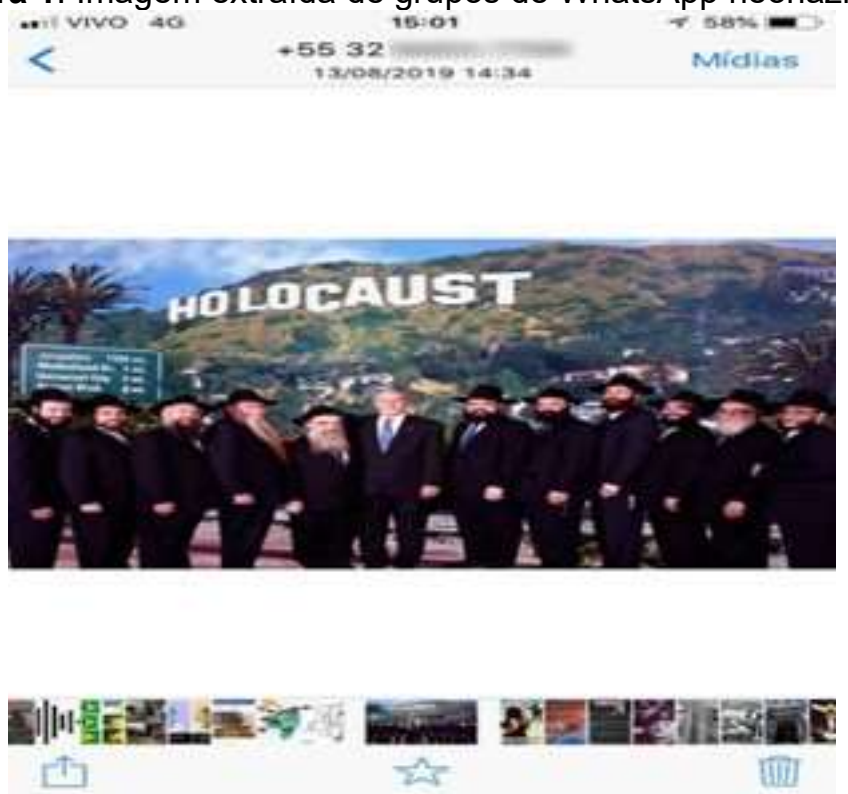

Fonte: Zanini (2019). - Reprodução. Fonte: FSP: 24 ago. 2019

A negação do genocídio dos judeus na $2^{\mathrm{a}}$ Grande Guerra é um tema recorrente nas mídias sociais, apoiado em autores negacionistas sem, contudo, ser demonstrado em forma documental validada pela comunidade de historiadores.

Outro aspecto relacionado a essa imagem é a ideia, amplamente divulgada nas mesmas condições por tais grupos, de que a existência de campos de concentração e câmaras de gás foi uma farsa criada por um suposto grupo judaico internacional que financia a indústria de cinema norte americana baseada em Hollywood.

A imagem pode referir-se ao apoio dos judeus norte-americanos à candidatura de George W. Bush para a presidência dos Estados Unidos da América em 200403; dessa forma, a montagem torna-se conveniente e significativa.

A placa de sinalização à esquerda, indicando que Jerusalém encontra-se a 7.586 milhas, e as montanhas icônicas de Los Angeles, onde está o letreiro de Hollywood, agora modificado por Holocaust, remetem e induzem à relação da denominada farsa da criação dos campos de concentração, ou seja, a ligação direta de Jerusalém e sua influência nos rumos dos roteiros e

\footnotetext{
30 Em 26/10/2004, o rabino ultraortodoxo Shalom Elyashiv, chefe espiritual da Lista Unificada da Tor (cinco deputados de 120 no parlamento israelense), declarou que o presidente Bush é o único candidato que pode ser considerado um "amigo autêntico de Israel". Essa é a primeira vez que uma figura rabínica dessa importância em Israel toma posição sobre a eleição americana. Em Israel viviam 15.000 ultraortodoxos de nacionalidade americana ou com dupla nacionalidade israelense e americana, de um total de 80.000 eleitores americanos que vivem no Estado hebreu, o que se torna um número expressivo a ser conquistado para essa candidatura.
} 
financiamentos de filmes hollywoodianos fortalecendo a "farsa" do extermínio durante a Segunda Guerra.

Por mais que evidências históricas coletadas de diversas formas e com vozes de múltiplos sujeitos testemunhas do período demonstrem o contrário, os dispositivos engendrados pelos grupos negacionistas acrescentam o ilusório (e o cinema não seria a arte da pura ilusão?) a fim de preservar o lugar privilegiado que a si próprios se atribuem no campo simbólico em uma manipulação cada vez mais sofisticada e especializada.

Se pensarmos na premissa de Maquiavel e sua frase "Governar é fazer crer", voltamos a refletir sobre as relações intrínsecas entre o poder e o imaginário e, em especial, ao uso da aparência para fortalecer o domínio político de determinados grupos e as condições elaboradas para criar aliados e inimigos.

Encontramos em Maquiavel toda uma teoria das aparências de que o poder se rodeia e que correspondem a outros tantos instrumentos de dominação simbólica. As "aparências" fixam as esperanças do povo no Príncipe, permitindo mobilizar e aumentar a energia daquele, fazer medo aos adversários, etc. O Príncipe, rodeando-se dos sinais do seu próprio prestígio e manipulando habilmente toda a espécie de ilusões (símbolos, festas, etc.), pode desviar em seu proveito as crenças religiosas e impor aos seus súditos o dispositivo simbólico de que retira o prestígio da sua própria imagem (BACZKO, 1985, p. 301).

Por fim, à guisa de considerações finais, procuramos refletir a importância da construção de estereótipos no arco da disseminação de informações e imagens em meios digitais.

O imaginário social torna-se inteligível e comunicável por intermédio da produção dos "discursos" nos quais e pelos quais se efetua a reunião das representações coletivas numa linguagem (BACZKO, 1985, p. 311).

As mídias não só aumentam o fluxo de informação, mas modelam suas características. A informação atomizada e fragmentada foca-se no hoje, mas recupera o que considera como importante de um passado que pode ser "adequado" e "adaptado" aos seus objetivos e, portanto, passível de manipulações, seleções e hierarquização de palavras e imagens.

A edição digital continua sendo um trabalho de edição com múltiplas intervenções; assim, seus refazeres e suas versões propõem e ressignificam o ciclo de trânsitos de um pré-conceito, de uma história e de uma imagem, reescrita, reeditada, republicada e posta em circulação, o que proporciona outros caminhos de recepção, alterando seus sentidos em novas práticas de leituras, mais rápidas, mais sintéticas e, por que não dizer, muitas vezes mais superficiais.

Adotando a premissa proposta por Chartier (2014, p. 38), "livros, sejam manuscritos ou impressos, sempre são resultado de múltiplas operações que supõem uma ampla variedade de decisões, técnicas e habilidades" - e aqui podemos pensar a ação de outros profissionais que lidam com a informação digital, como também aqueles produtores de conteúdo que pretendem atingir determinadas parcelas sociais em um processo de persuasão e convencimento -, consideramos que, ao invés do termo livros, podemos substituir por tuítes e mensagens rápidas veiculadas pelos aplicativos de celulares e refletir acerca das autorias e edições de mensagens. Claro que as práticas de leitura podem ser deslocadas ou subvertidas por seus leitores, mas isso pode ser objeto de análise em outra situação e texto, que não cabe aqui.

A escrita de uma História dos judeus é complexa pelos elementos que trazem em seu processo. A escrita de uma História dos judeus no Brasil implica em um processo contraditório e mais complexo ainda pelos imaginários construídos desde a colonização. A singularidade dessa escrita encontra perigos escondidos em discursos espraiados em mídias que divulgam uma história pública que recorta fatos e negam evidências documentais que comprovam os arbítrios inimagináveis.

Cabe, porém, muito mais que alertar, desconstruir e apontar a barbárie alimentada por grupos denominados nacionalistas, imbuídos de ideais e imaginários extremistas que pregam a 
violência e negam a liberdade e a tolerância para todos que não se enquadrem em seu projeto salvacionista.

\section{Referências}

ARENDT, Hannah. We Refugee. In: ROBINSON, Marc (ed.). Altogether Elsewhere. Writers on Exile. Boston; London: Faber and Faber, 1994, p. 110-119.

ARTE Degenerada. In: ENCICLOPÉDIA Itaú Cultural de Arte e Cultura Brasileiras. São Paulo: Itaú Cultural, 2020. Disponível em: http://enciclopedia.itaucultural.org.br/termo328/arte-degenerada. Acesso em: 24 de Nov. 2020. Verbete da Enciclopédia.

BACZKO, Bronislaw. A imaginação social. In: LEACH, Edmund et al. Anthropos-Homem. Lisboa: Imprensa Nacional; Casa da Moeda, 1985, p. 296-332.

BECKER, Jean-Jacques. A opinião Pública. In: RÉMOND, René (org.). Por uma História Política. Tradução: Dora Rocha. 2. ed. Rio de Janeiro: FGV, 2003, p. 185-211.

BERTONHA, João Fábio. A direita radical brasileira no século XX: do Monarquismo e das Ligas Nacionalistas ao fascismo e à ditadura militar (1889-2011). Studia Historica. História Contemporánea, v. 30, p. 133-150, 2012.

BETZ, Hans-Georg. The new politics of resentment: radical right-wing populist parties in Western Europe. Comparative Politics, v. 25, n. 4, p. 413-427, 1993.

BRENNER, Michael. Breve História dos Judeus. São Paulo: Martins Fontes, 2013.

CALDEIRA NETO, Odilon. Memória e Justiça: o negacionismo e a falsificação da história. Antíteses, v. 2, n. 4, p. 1097-1123, jul./dez. 2009. Disponível em: http://www.uel.br/revistas/uel/index.php/antiteses/article/view/2507. Acesso em: 15 maio 2020.

CARNEIRO, Maria Luiza Tucci. Cidadão do Mundo: o Brasil diante do Holocausto e dos judeus refugiados do Nazifascismo (1933-1948). São Paulo: Perspectiva: Fapesp, 2010.

CARNEIRO, Maria Luiza Tucci. Rompendo o silêncio: a historiografia sobre o antissemitismo no Brasil. Cadernos de História, Belo Horizonte, v. 13, n. 18, p. 79-97, maio 2012. Disponível em: http://seer.pucminas.br/index.php/cadernoshistoria/article/view/P.2237-8871.2012v13n18p79.

Acesso em: 20 nov. 2018.

CARVALHO, Bruno Leal Pastor de. O negacionismo do Holocausto na internet: o caso da "Metapédia - a enciclopédia alternativa". Faces da História, Assis-SP, v. 3, n. 1, p. 5-23, jan.-jun. 2016.

CASTORIADIS, Cornelius. A instituição imaginária da sociedade. Rio de Janeiro: Paz e Terra, 1982.

CHARTIER, Roger. A mão do autor e a mente do editor. Trad. George Schlesinger. São Paulo: Unesp, 2014.

CHARTIER, Roger. O mundo como representação. In: CHARTIER, Roger. À beira da falésia: a história entre incertezas e inquietude. Trad. Patrícia Chittoni Ramos. Porto Alegre: UFRGS, 2002, p. 61-80.

CHASIN, José. O integralismo de Plínio Salgado: forma de regressividade no capitalismo hipertardio. Bauru: EDUSC, 1999

COBO ROMANÍ, Cristóbal; PARDO KUKLINSKI, Hugo. Planeta Web 2.0. Inteligencia colectiva o medios fast food Planeta Web 2.0. Inteligencia colectiva o medios fast food. Barcelona; México, DF, 
COHEN, Jeremy. The Friars and the Jews: The Evolution of Medieval Anti-Judaism. Ithaca, NY: Cornell University Press, 1982.

COSTA, Machado. Conheça o Gab, a rede social sem filtros que apoia Bolsonaro. Veja, São Paulo, 7 out. 2018. Disponível em: https://veja.abril.com.br/economia/conheca-o-gab-a-rede-social-semfiltros-que-apoia-bolsonaro/ Acesso em: 21 mar. 2020.

CYTRYNOWICZ, Roney. Além do Estado e da ideologia: imigração judaica, Estado-Novo e Segunda Guerra Mundial. Revista Brasileira de História, v. 22, n. 44, p. 393-423, 2002.

DIAS, Adriana Abreu Magalhães. Um mergulho no universo neonazista. [Entrevista cedida a] Luiz Sugimoto. Jornal da Unicamp, Campinas, 28 set. 2018. Disponível em: https://www.unicamp.br/unicamp/ju/noticias/2018/09/28/um-mergulho-no-universo-neonazista.

Acesso em: 12 mar. 2020.

FIORUCCI, Rodolfo. O anticomunismo integralista nos anos 1930: o caso da revista Anauê! In: PRIORI, Angelo; MATHIAS, Meire; FIORUCCI, Rodolfo. O anti comunismo e a cultura autoritária no Brasil. Curitiba: Prismas, 2017, p. 11-38.

FOLHA PRESS. No WhatsApp, grupos reúnem até quem nega o Holocausto e apoia o nazismo. $O$ Tempo, Belo Horizonte, 25 ago. 2019. Disponível em: https://www.otempo.com.br/brasil/nowhatsapp-grupos-reunem-ate-quem-nega-o-holocausto-e-apoia-o-nazismo-1.2226831. Acesso em: 25 fev. 2020.

FUCS, José. CEO do Gab comemora 'invasão' da direita brasileira. O cão que fuma, Rio de Janeiro, 23 ago. 2018. Disponível em: http://www.caoquefuma.com/2018/08/ceo-do-gab-comemorainvasao-da-direita.html. Acesso em: 21 mar. 2020.

GOMES, Ângela de Castro. História, historiografia e cultura política no Brasil: algumas reflexões. In: SOIHET, Rachel; BICALHO, Maria Fernanda \& GOUVÊA, Maria de Fátima (orgs.). Culturas políticas: ensaios de história cultural, história política e ensino de história. v. 1. Rio de Janeiro: Mauad, 2005, p. 21-44.

KLEMPERER, Viktor. LTI: a linguagem do Terceiro Reich. Rio de Janeiro: Contraponto, 2009.

KUSCHNIR, Karina; PIQUET-CARNEIRO, Leandro. As dimensões subjetivas da política: cultura política e Antropologia. Revista de Estudos Históricos, v. 2, n. 24, p. 227-250, 1999.

LESSER, Jeffrey. Judeus salvam judeus: os estereótipos e a questão dos refugiados no Brasil, 1935-1945. In: GRINBERG, Keila (org.). Os judeus no Brasil: inquisição, imigração e identidade. Rio de Janeiro: Civilização Brasileira, 2005, p. 315-334.

LESSER, Jeffrey. O Brasil e a Questão Judaica - Imigração, Diplomacia e Preconceito. Rio de Janeiro: Imago, 1995.

LESSER, Jeffrey; CYTRYNOWICZ, Roney. Prefácio. BRENNER, Michael. Breve História dos Judeus. São Paulo: Martins Fontes, 2013.

MACHADO, Maria Berenice da Costa. Debates nas campanhas presidenciais: Brasil 1989-2010. In: Encontro Nacional de História da Mídia, 8., 2011, Guarapuava - PR. Anais [...]. Guarapuava: Rede Alcar, 2011.

MAGALHÃES, Wallace Lucas. O imaginário social como um campo de disputas: um diálogo entre Baczko e Bourdieu. Albuquerque - Revista de História, Aquidauana, v. 8, n. 16, p. 92-110, jul.-dez. 2016. 
MALERBA, Jurandir. Os historiadores e seus públicos: desafios ao conhecimento histórico na era digital. Revista Brasileira de História, São Paulo, v. 37, n. 74, p. 135-154, 2017.

METAPEDIA. Missão. São Francisco, CA, EUA, 2420 set. 2011. Disponível em: https://pt.metapedia.org/wiki/Metapedia:Missão Acesso em: 21 mar. 2020.

MICHMAN, Dan. The Emergence of Jewish Ghettos During the Holocaust. Cambridge: Cambridge University Press, 2011.

MILGRAM, Avraam. Salvamento de judeus por judeus no Holocausto - oxímoro histórico. Arquivo Maaravi: Revista Digital de Estudos Judaicos da UFMG, Belo Horizonte, v. 11, p. 18-37, 2017.

MILGRAM, Avraham. Os judeus do Vaticano. A tentativa de salvação de católicos - não-arianos da Alemanha ao Brasil através do Vaticano (1939-1942). São Paulo: Imago, 1994.

MORIN, Edgar. O mundo moderno e a questão judaica. Rio de Janeiro: Bertrand Brasil, 2007.

MOURA, Nando. Hitler era de DIREITA? YouTube, San Bruno, CA, 29 out. 2015. Vídeo (9 min). Disponível em: https://www.youtube.com/watch?v=nmFAPqzaAz8\&t=56s. Acesso em: 25 fev. 2020.

NIRENBERG, David. Anti-judaism. The Western Tradition. New York: Norton \& Company, 2014.

NOVINSKY, Anita. O legado do judaísmo à civilização brasileira. In: LEWIN, H. (coord.). Identidade e cidadania: como se expressa o judaísmo brasileiro. Rio de Janeiro: Centro Edelstein de Pesquisas Sociais, 2009, p. 1-8.

OLIVEIRA, Filipe. Facebook chega a 127 milhões de usuários mensais no Brasil. Folha de S.Paulo, São Paulo, 18 jul. 2018. Disponível em: https://www1.folha.uol.com.br/tec/2018/07/facebook-chegaa-127-milhoes-de-usuarios-mensais-no-brasil.shtml. Acesso em: 18 set. 2020.

PEGIDA BRASIL. Patriotas Europeus contra a Islamização do Ocidente. Disponível em: https://www.facebook.com/groups/769144969817540/. Facebook, Cambridge, MA, 2020. Acesso em: 25 fev. 2020.

PODER360. Descendente de índio, vice de Bolsonaro fala que indígenas são indolentes - 06 ago. 2018. YouTube, San Bruno, CA, 7 ago. 2018. Vídeo (2 min). Disponível em: https://www.youtube.com/watch?v=uPqNLiFHxXo. Acesso em: 24 dez. 2018.

PRIORI, Angelo Aparecido; BRUNELO, Leandro. Cultura política: reflexão conceitual e interface com a história política. In: PRIORI, Angelo Aparecido; BRUNELO, Leandro (orgs.). História política e a sua escrita: temas, abordagens e problematizações. Curitiba: Prismas, 2018. p. 15-38.

RABINOVITCH, Gérard. Schoá: Sepultos nas nuvens. São Paulo: Perspectiva, 2004.

RAGUSA, Helena. Livros Didáticos, História Pública e o conhecimento histórico produzido sobre o Judeu no Brasil: Diálogos e Perspectivas. História \& Ensino, v. 24, p. 337-361, 2018.

RYAN, Johnny. A history of the internet and the digital future. Londres: Reaktion Books, 2010.

SIRINELLI, Jean-François. Os intelectuais. In: RÉMOND, René (org.). Por uma história política. 2. ed. Rio de Janeiro: FGV, 2003, p. 231-269.

SORJ, Bila. Anti-semitismo na Europa hoje. Novos estudos - CEBRAP, São Paulo, n. 79, p. 97-115, nov. 2007.

SORLIN, Pierre. O anti-semitismo alemão. São Paulo: Perspectiva, 1974.

TAGUIEFF, Pierre-André. L'antisionisme est devenu la forme dominante de la judéophobie. 
[Entrevista cedida] Noémie Halioua. L'Arche Magazine, Paris, 11 mar. 2016. Disponível em: https://larchemag.fr/2016/03/11/2316/pierre-andre-taguieff-lantisionisme-est-devenu-la-formedominante-de-la-judeophobie. Acesso em: 18 set. 2020.

TRAVERSO, Enzo. The end of Jewish Modernity. Pluto Press. London: 2016.

WODAK, Ruth. Prejudice, Racism, and Discourse In: PELINKA, Anton; Karin Bischof; STÖGNER, Karin (eds.). Handbook of Prejudice. Amherst, NY: Cambria Press, 2009, p. 409-443.

WODAK, Ruth. The Radical Right and Antisemitism. In: RYDGREN, Jens (ed.). The Oxford Handbook of the Radical Right. Oxford University Press, 2018, p. 1-33.

ZANINI, Fábio. Grupos de mensagens negam holocausto louvam de Hitler a Enéas e propagam nazismo. Folha de S.Paulo, São Paulo, 24 ago. 2019. Disponível em: https://www1.folha.uol.com.br/poder/2019/08/grupos-de-mensagens-negam-holocausto-louvamde-hitler-a-eneas-e-propagam-nazismo.shtml?utm_source=facebook\&utm_medium=socialmedia\&utm_campaign=noticias\&utm_content=geral. Acesso em: 03 dez. 2018.

\section{Notas de autoria}

Ana Heloisa Molina é professora associada da Universidade Estadual de Londrina. Realizou estágio pós-doutoral junto ao Programa de Pós-Graduação em História da Universidade Federal Fluminense, sob a supervisão da Prof ${ }^{a}$ Dra. Ana Maria Mauad (2012-2013); e também junto ao Programa de Pós-Graduação em Multimeios do Instituto de Artes da Unicamp (2017), sob a supervisão da Profa Dra. lara Lis Franco Schiavinatto. É licenciada em História e tem doutorado em História pela Universidade Federal do Paraná. E-mail: ahmolina@uel.br.

Helena Ragusa é doutoranda do Programa de Pós-Graduação em História na Universidade Estadual de Maringá na linha de pesquisa "História Política" e bolsista CAPES. É licenciada em História (1998), Especialista (2001) e Mestre (2012) em História Social com ênfase em História e Ensino, sempre pela Universidade Estadual de Londrina. Tem experiência na área de História, com ênfase em História Política, História Pública, História e Ensino, Livros Didáticos, História dos Cristãos-Novos e História Judaica. E-mail: ragusa@uel.br.

\section{Como citar esse artigo de acordo com as normas da revista}

MOLINA, Ana Heloisa; RAGUSA, Helena. Os novos contornos do antissemitismo, a construção de imaginários pela mídia no Brasil e a escrita da História: singularidades e perigos. Sæculum - Revista de História, v. 25, n. 43, p. 361-379, 2020.

\section{Contribuição de autoria}

Ana Heloisa Molina: Escrita conjunta do texto com base em pesquisa desenvolvida pelas duas autoras. Revisão bibliográfica.

Helena Ragusa: Escrita conjunta do texto com base em pesquisa desenvolvida pelas duas autoras. Revisão final.

\section{Financiamento}

O presente trabalho foi realizado com apoio da Coordenação de Aperfeiçoamento de Pessoal de Nível Superior - Brasil (CAPES) - Código de Financiamento 001.

\section{Consentimento de uso de imagem}

Não se aplica

\section{Aprovação de comitê de ética em pesquisa}

Não se aplica

\section{Licença de uso}


Este artigo está licenciado sob a Licença Creative Commons CC-BY. Com essa licença você pode compartilhar, adaptar, criar para qualquer fim, desde que atribua a autoria da obra.

\section{Histórico}

Recebido em 15/08/2020.

Modificações solicitadas em 12/09/2020.

Aprovado em 24/10/2020. 